RIZZOTO, G. et al. Efeitos da adição de glicerol e etilenoglicol associados sobre parâmetros de viabilidade espermática na criopreservação de sêmen canino. PUBVET, Londrina, V. 8, N. 22, Ed. 271, Art. 1808, Novembro, 2014.

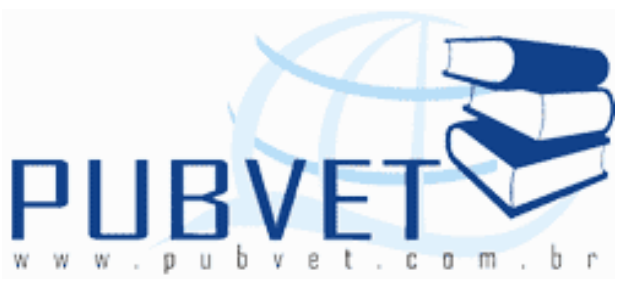

PUBVET, Publicações em Medicina Veterinária e Zootecnia.

\title{
Efeitos da adição de glicerol e etilenoglicol associados sobre parâmetros de viabilidade espermática na criopreservação de sêmen canino
}

Guilherme Rizzoto ${ }^{1,3}$, Fabiana Moreira ${ }^{1}$, Antônio Sérgio Varela Junior ${ }^{4}$, Maria Eduarda Bicca Dode ${ }^{3}$, Márcia de Oliveira Nobre ${ }^{2}$, Carine Dahl Corcini ${ }^{1 *}$

${ }^{1}$ Grupo de pesquisa ReproPel - Faculdade de Veterinária Universidade Federal de Pelotas- UFPel

${ }^{2}$ Grupo de Pesquisa CLINPET - Faculdade de Veterinária - UFPel

${ }^{3}$ Acadêmico em Medicina Veterinária - UFPel

${ }^{4}$ RAC- Universidade Federal de Rio Grande, Campus Universitário s/n - Caixa Postal 354 - CEP 96010-900

E-mail: corcinicd@gmail.com

\section{Resumo}

Agentes crioprotetores (ACPs), são substâncias adicionadas no diluente seminal com função de reduzir os danos aos espermatozoides durante a congelação. Porém, esta prática é um processo que acarreta lesões e/ou morte celular que podem inviabilizar a fecundação. O objetivo deste trabalho foi avaliar o efeito da associação dos ACPS Glicerol (G) e Etilenoglicol (E) junto ao diluente Tris-gema (TG) sobre os parâmetros de integridade e funcionalidade das células espermáticas criopreservadas de cães. . Dez ejaculados de machos caninos foram diluídos em 3 tratamentos:, $5 \%$ G (T1), 5\% E (T2) e G+E 
RIZZOTO, G. et al. Efeitos da adição de glicerol e etilenoglicol associados sobre parâmetros de viabilidade espermática na criopreservação de sêmen canino. PUBVET, Londrina, V. 8, N. 22, Ed. 271, Art. 1808, Novembro, 2014.

(concentração final de $2,5 \%+2,5 \%$ ) (T3). Os ejaculados foram avaliados, prontamente diluídos, envasados em palhetas de $0,25 \mathrm{ml}$ e criopreservados em máquina de congelamento seminal. As amostras foram avaliadas pósdescongelamento quanto a motilidade espermática (ME), integridade de acrossoma (IA), integridade de membrana (IM), integridade de DNA (ID), funcionalidade de mitocôndria (FM), taxa de penetração heteróloga com óocitos suínos (TP) e número de espermatozoides/oócitos penetrados (NE). A ME foi avaliada em microscópio óptico e as análises de IA, IM, ID e FM foram avaliadas em microscópio de fluorescência (400X) com corantes fluoróforos específicos para cada análise. A fertilização foi realizada em gota de $750 \mu \mathrm{l}$ de M2 com HEPES contendo 0,4\% de BSA acrescido de $250 \mu$ le sêmen, sendo posteriormente recuperados e corados com Hoescht $33342(10 \mu \mathrm{g} / \mathrm{ml})$ para então avaliar a TP e o NE em microscópio de fluorescência (400X). Não foi observado diferença estatística entre os tratamentos quanto a ME, IM, ID e FM. Em relação a IA o T2 diferiu $(P<0,05)$ dos tratamentos 1 e $3 \quad(24,8 \pm$ 18,$3 ; 50,2 \pm 25,4 ; 38,1 \pm 27,5 ;$ respectivamente). Para a TP os melhores resultados foram do T3 $(9,8 \pm 9,3)$ e T2 $(8,5 \pm 1,51)$ diferindo estatisticamente do tratamento T1 $(1,3 \pm 1,3)$. Na análise do NE o T3 apresentou o melhor resultado $(0,9 \pm 0,8)$, apresentando diferença estatística do $T 1(0,2 \pm 0,2)$ e do T2 $(0,13 \pm 0,13)$. Concluiu-se, portanto, que a associação de glicerol e etilenoglicol é uma alternativa eficaz para criopreservação de sêmen canino.

\section{Effects of adding glycerol and ethylene glycol associated in espermatic viability parameters in canine semen criopreservation}

\section{Abstract}

Cryoprotectors (ACPs) are substances added in seminal extenders with function to reduce damage to spermatozoa during freezing. However, this practice is a process that leads to injury and / or cell death that may decrease fertilization. The objective of this study was to evaluate the association of 
RIZZOTO, G. et al. Efeitos da adição de glicerol e etilenoglicol associados sobre parâmetros de viabilidade espermática na criopreservação de sêmen canino. PUBVET, Londrina, V. 8, N. 22, Ed. 271, Art. 1808, Novembro, 2014.

ACPS Glycerol (G) and ethylene glycol (E) with the Tris-egg yolk extender (TG) on the parameters of integrity and functionality of cryopreserved canine sperm cells. Ten canine male ejaculates were diluted in 3 treatments: $5 \% \mathrm{G}(\mathrm{T} 1)$, and $5 \%$ (T2) and G+ E (final concentration of $2.5 \%+2.5 \%$ ) (T3). The ejaculates were evaluated, readily diluted, packaging in $0.25 \mathrm{ml}$ straws and cryopreserved in seminal freezing machine. Post-thawed samples were evaluated for sperm motility (SM), acrosome integrity (AI), membrane integrity (MI), DNA integrity (DI), mitochondrial functionality (MF), rate of penetration with heterologous porcine oocytes (RP) and number of sperm /penetrated oocytes (NS). The SM was evaluated under a light microscope and the analyzes of AI, MI, DI and MF were assessed with a fluorescence microscope (400X) with specific fluorophores dyes for each analysis. Fertilization was performed at $750 \mu \mathrm{l}$ drop of M2 HEPES containing $0.4 \%$ BSA plus $250 \mu \mathrm{l}$ of sêmen, the oocytes were subsequently recovered and stained with Hoechst $33342(10 \mu \mathrm{g} / \mathrm{ml})$ and submitted to the evaluation of RP and NS on fluorescence microscope (400X). No statistical difference was observed between treatments for SM, MI, DI and FM. Regarding IA the T2 differ ( $P$ $<0.05)$ from the treatments 1 and $3(24.8 \pm 18.3,50.2 \pm 25.4,38.1 \pm 27.5$, respectively). The best results for RP were T3 $(9.8 \pm 9.3)$ and T2 $(8.5 \pm 1.51)$ that were statistically different from T1 $(1.3 \pm 1.3)$. In the analysis of NS the T3 showed the best results $(0.9 \pm 0.8)$, showing statistical difference of T1 $(0.2 \pm 0.2)$ and $\mathrm{T} 2(0.13 \pm 0.13)$. Therefore the combination of glycerol and ethylene glycol is an effective alternative for cryopreservation of canine semen.

\section{Introdução}

Nas últimas décadas, os criadores de cães vêm apresentando um maior interesse pelas biotecnologias associadas ao sêmen desta espécie (Concannonet al.,1889; Farstad,1996; Penã et al.,2000). Tal fato advém principalmente de dois importantes motivos, o início do comércio internacional de sêmen canino e o estabelecimento de bancos genéticos de reprodutores de 
RIZZOTO, G. et al. Efeitos da adição de glicerol e etilenoglicol associados sobre parâmetros de viabilidade espermática na criopreservação de sêmen canino. PUBVET, Londrina, V. 8, N. 22, Ed. 271, Art. 1808, Novembro, 2014.

alto valor zootécnico através da criopreservação (De Los Reyes,2004), que tem como função reduzir os danos aos espermatozoides durante o congelamento e descongelamento (England,1993).

Porém,esta prática é um processo que acarreta lesões e/ou morte celular que podem inviabilizar a fecundação (Bouchardet al., 1990; Lopez-Bejar et al., 1994; Silva et al.,1995;). Buscando contornar estas barreiras, substâncias denominadas agentes crioprotetores (ACPs), passaram a ser empregados como componentes do diluente seminal (England,1993). Efeitos tóxicos podem ser observados com a utilização destes agentes, devido à formação de subprodutos como ácido glicólico e o oxalato devido a metabolização do Etilenoglicol (Hammerstd et al., 1992). Além disto, o glicerol é um componente natural das membranas celulares e apresenta fácil metabolização (Castro et al., 2011). Relatos mostram que este produto pode afetar a organização citoplasmática, alterar a estabilidade e permeabilidade da bicamada lipídica (Corley et al., 2005). Em adição muitos estudos já demonstraram que a toxicidade dos ACPs é um ponto crítico para sua utilização e tal toxidade é concentração-dependente, sendo, portanto, seu uso indicado somente na concentração exata para que exista predominância dos efeitos protetores sobre os efeitos tóxicos (McLaughin et al., 1992; Watson 1995, Holt, 2000).

O presente trabalho buscou comparar a associação dos ACPS Glicerol e Etilenoglicol sobre os parâmetros de integridade e funcionalidade das células espermáticas criopreservadas de cães.

\section{Materiais e Métodos}

\subsection{Animais/Amostras}

Foram utilizados 2 cães da raça Shih-tzu e 1 cão da raça Buldogue Americano, pertencentes a um criador local, mantidos em condições de alimentação e habitação adequadas. Foram realizadas 4 coletas seminais, respeitando a disponibilidade e bem-estar na utilização dos reprodutores, totalizando 12 ejaculados. As coletas foram feitas através de manipulação 
RIZZOTO, G. et al. Efeitos da adição de glicerol e etilenoglicol associados sobre parâmetros de viabilidade espermática na criopreservação de sêmen canino. PUBVET, Londrina, V. 8, N. 22, Ed. 271, Art. 1808, Novembro, 2014.

digital (Forsberg,1995) em condições isotérmicas, sendo utilizada para criopreservação somente a fração rica em espermatozoides. Somente os ejaculados com motilidade total $>80 \%$ foram utilizados.

\subsection{Avaliação dos ejaculados}

A avaliação de motilidade espermática foi realizada imediatamente após a coleta da fração rica em espermatozoides através de microscopia óptica (CHK2-F-GS, Olympus OpticalCo.Ltda.) sob aumento de 200X (Christiansem, 1986)

A integridade de membrana plasmática foi avaliada através das sondas fluorescentes diacetato de carboxifluoresceína (CFDA) (C4916-25mg, Sigma ChemicalCompany, St. Louis, MO, USA) e Iodeto de Propídio (IP) (P4170-1g, Sigma Chemical Company, St. Louis, MO, USA), conforme descrito por Harrison \& Vickers (1990). Esta avaliação foi feita em microscópio de epifluorescência (E200, Nikon Instruments Inc.) em aumento de 400X utilizando filtro WU com excitações de 450-490nm. As células que apresentavam fluorescência verde foram consideradas íntegras, enquanto as células com fluorescência vermelha e verde/vermelha foram consideradas danificadas.

Para a avaliação da integridade de Acrossoma (Corcini et al., 2012a) foram utilizandas sondas Conjugado de Lectina de Arachis hypogaea FITC (20 $\mathrm{mg} / \mathrm{mL}$ ) (L7381, Sigma Chemical Company, St. Louis, MO, USA) e IP. As lâminas foram avaliadas em aumento de 1000 x, em microscópio de epifluorescência, em filtro WU com excitações de 450-490nm. Foram consideradas células com acrossomas íntegros aquelas que apresentavam fluorescência verde no acrossoma e com morfologia normal. Quando toda a célula não era corada e a coloração verde não era aparente ou quando a morfologia acrossômica estava anormal, foi considerado danificado.

A integridade mitocondrial foi avaliada com o uso de uma sonda específica, Rodamina 123 (Rh123) (R8004, Sigma Chemical Company, St. Louis, MO, 23 USA), juntamente com IP para a discriminação entre os 
RIZZOTO, G. et al. Efeitos da adição de glicerol e etilenoglicol associados sobre parâmetros de viabilidade espermática na criopreservação de sêmen canino. PUBVET, Londrina, V. 8, N. 22, Ed. 271, Art. 1808, Novembro, 2014.

espermatozoides vivos e mortos (Grasaet al., 2004). As células foram avaliadas em aumento de 400x em microscópio de epifluorescência (E200, Nikon), em filtro WU com excitações de 450-490 nm. As células que apresentavam a peça intermediária com uma intensa fluorescência verde foram consideradas com mitocôndrias integras (funcionalmente ativas), enquantoas células sem intensa fluorescência verde na peça intermediária foram consideradas não funcionais.

A integridade de DNA foi avaliada segundo descrito por Gandiniet al. ${ }^{20}$.

Foi realizada a avaliação de 200 células espermáticas por lâmina para a integridade de membrana, de acrossoma, de DNA e funcionalidade mitocondrial.

Para o teste de penetração in vitro a metodologia utilizada por Corcini et al., 2012b sendo utilizados 30 oócitos por palheta de cada macho sem repetição. Para co-incubação dos gametas utilizou-se uma gota de $750 \mu \mathrm{L}$ de meio M2 (SIGMA 7167) com HEPES contendo 0,4\% de BSA acrescido de 250 $\mu \mathrm{L}$ de sêmen, permanecendo incubado em banho-maria por $2 \mathrm{~h}$ a $37^{\circ} \mathrm{C}$. Após esse período, os oócitos foram recuperados, lavados, submetidos ao corante Hoescht $33342(10 \mu \mathrm{g} / \mathrm{mL})$ e avaliados em microscópio de epifluorescência sob 400x. Contou-seo número de oócitos que continham espermatozoides em seu interior, assim como o número de espermatozoides em cada oócito.

\subsection{Diluente}

Foram adicionados ao diluente tris-gema (Iguer Ouda, 2001) 10\% de glicerol (GLI), $10 \%$ de etilenoglicol (EG) e $5 \%$ de GLI + 5\% de EG constituindo assim em 3 tratamentos: T1, T2 e T3, respectivamente.

\subsection{Processamento do sêmen}

O sêmen foi diluído $1 / 1(\mathrm{v} / \mathrm{v})$ com diluente tris-gema a $37^{\circ} \mathrm{C}$ quando da coleta, sendo transportado até o laboratório que foi dividido em 3 partes iguais que foram adicionados aos diferentes tratamentos em $1 / 1(\mathrm{v} / \mathrm{v})$. Os tratamentos T1, T2 e T3 alcançaram as concentrações de 5\%, 5\% e 
RIZZOTO, G. et al. Efeitos da adição de glicerol e etilenoglicol associados sobre parâmetros de viabilidade espermática na criopreservação de sêmen canino. PUBVET, Londrina, V. 8, N. 22, Ed. 271, Art. 1808, Novembro, 2014.

2,5\%+2,5\% de GLI e EG, respectivamente. O sêmen permaneceu em contato com os crioprotetores por 10 minutos sendo então envasado em palhetas de $0,25 \mathrm{ml}$. O sêmen a $20^{\circ} \mathrm{C}$ foi então alocado na máquina de congelamento com curva específica para sêmen canino (Temperatura $(T)$ inicial de $20^{\circ} \mathrm{C}$, decréscimo de $0,5^{\circ} \mathrm{C} / \mathrm{min}$ até a $\mathrm{T}$ de $4^{\circ} \mathrm{C}$, estabilização por 10 minutos, decréscimo de $1{ }^{\circ} \mathrm{C} / \mathrm{min}$ até $-10^{\circ} \mathrm{C}$, decréscimo de $5 \% / \mathrm{min}$ até $-30^{\circ} \mathrm{C}$, decréscimo de $\$^{\circ} \mathrm{C} / \mathrm{min}$ até $-43^{\circ} \mathrm{C} \mathrm{T}$ final) (FREEZE CONTROL $\Re$ Modelo 5500), sendo posteriormente alocado em botijão de nitrogênio líquido.

O descongelamento a $37^{\circ} \mathrm{C}$ por 30 segundos foi realizado 30 dias após a última rotina de congelamento. As amostras foram novamente submetidas aos exames de motilidade espermática, integridade de acrossoma, de DNA, de membrana, funcionalidade de mitocôndria e teste de penetração heteróloga com oócitos.

\subsection{Análise estatística}

Os parâmetros de motilidade, funcionalidade de mitocôndria, integridade da membrana, integridade do acrossoma, número de espermatozóides por oócito e integridade do DNA foram comparados entre os tratamentos. Foi realizado o teste de normalidade Shapiro-wilk, e após procedeu-se a análise de Kruskal Wallis. Para o teste de penetração foi utilizando o teste de Quiuadrado. Todas as análises estatísticas foram conduzidas através do software Statistix $®$ (2008).

\section{Resultados:}

A motilidade espermática no sêmen fresco foi de $81,0 \pm 20,3 \%$. Não foi observado diferença $(P>0,05)$ entre os resultados obtidos para motilidade dos três tratamentos pós-descongelamento (Tab.1).

A taxa de integridade de mitocôndria no ejaculado fresco foi de $78,8 \pm$ $33,8 \%$, e nas análises posteriores ao descongelamento não se observou variação entre os tratamentos $(P>0,05)$ (Tabela 2$)$. Os valores encontrados para a integridade de membrana $(91,4 \pm 5,7 \%$ no sêmen fresco) e integridade 
RIZZOTO, G. et al. Efeitos da adição de glicerol e etilenoglicol associados sobre parâmetros de viabilidade espermática na criopreservação de sêmen canino. PUBVET, Londrina, V. 8, N. 22, Ed. 271, Art. 1808, Novembro, 2014.

de DNA (94,4 $\pm 4,5 \%$ no ejaculado fresco) pós-descongelamento, também não apresentaram diferença estatística entre nenhum dos tratamentos (Tabela 2).

A integridade de acrossoma foi de $81,7 \pm 5,2 \%$ no sêmen fresco. Pósdescongelamento o T2 apresentou percentual menor diferindo estatisticamente dos tratamentos T1 e T3 (Tabela 2).

Tabela 1. Taxa de motilidade espermática (\%) (média \pm desvio padrão da média) obtidas do descongelamento de sêmen canino congelado nos três tratamentos utilizados*.

\begin{tabular}{cc}
\hline Tratamento & Mot. Espermática \% \\
\hline T1 & $13 \pm 13,0$ \\
T2 & $14 \pm 13,9$ \\
T3 & $18 \pm 18,0$ \\
\hline
\end{tabular}

Os tratamentos não diferiram estatisticamente entre si $(P>0,05)$.

*T1: Tris-gema $5 \%$ de glicerol;

T2: Tris-gema $5 \%$ de etilenoglicol;

T3: Tris-gema $2,5 \%$ glicerol $+2,5 \%$ de etilenoglicol.

Tabela 2. Integridade de membrana, acrossoma e DNA e funcionalidade de mitocôndria (\%) (média \pm erro padrão da média) obtida após o descongelamento de sêmen canino diluído nos três tratamentos utilizados*

\begin{tabular}{ccccc}
\hline Tratamento & $\begin{array}{c}\text { Fun. } \\
\text { Mitocôndria }\end{array}$ & $\begin{array}{c}\text { Int. } \\
\text { Membrana }\end{array}$ & $\begin{array}{c}\text { Int. } \\
\text { Acrossoma }\end{array}$ & Int. DNA \\
\hline T1 & $12,6 \pm 12,6$ & $52,7 \pm 25,4$ & $50,2 \pm 25,4^{\mathrm{a}}$ & $94,1 \pm 9,0$ \\
T2 & $16,5 \pm 12$ & $46,9 \pm 25,9$ & $24,8 \pm 18,3^{\mathrm{b}}$ & $88,2 \pm 27,3$ \\
T3 & $15,8 \pm 10$ & $60,1 \pm 26,4$ & $38,1 \pm 27,5^{\mathrm{a}}$ & $96,0 \pm 6,5$ \\
\hline a,b Expoentes diferentes indicam diferença estatística na coluna $(\mathrm{P}<0,05)$. \\
*T1: Tris-gema 5\% de glicerol; \\
T2: Tris-gema 5\% de etilenoglicol; \\
T3: Tris-gema 2,5\% glicerol + 2,5\% de etilenoglicol.
\end{tabular}


RIZZOTO, G. et al. Efeitos da adição de glicerol e etilenoglicol associados sobre parâmetros de viabilidade espermática na criopreservação de sêmen canino. PUBVET, Londrina, V. 8, N. 22, Ed. 271, Art. 1808, Novembro, 2014.

A taxa de penetração foi inferior $(P<0,05)$ no $T 1$ quando comparada -ao T2 e T3, enquanto que o T2 e o T3 não diferiram ( $P>0,05)$ entre si (Figura 2). Quanto ao número de espermatozoides/oócitos penetrados o T3 apresentou o melhor resultado $(P<0,05)$ quando comparado com T1 e T2 que não diferiram entre si (Tabela 3).

Tabela 3. Taxa de penetração heteróloga com oócitos suínos (\%) e número de espermatozoides/oócitos penetrados (média \pm erro padrão da média) obtidas do descongelamento de sêmen canino diluído nos três tratamentos utilizados*.

\begin{tabular}{ccc}
\hline Tratamentos & $\begin{array}{c}\text { Taxa de } \\
\text { Penetração }\end{array}$ & $\begin{array}{c}\mathbf{N}^{\circ} \\
\text { sptz/oócitos }\end{array}$ \\
\hline T1 & $1,3 \pm 1,3^{\mathrm{b}}$ & $0,2 \pm 0,2^{\mathrm{b}}$ \\
T2 & $8,5 \pm 1,51^{\mathrm{a}}$ & $0,13 \pm 0,03^{\mathrm{b}}$ \\
T3 & $9,8 \pm 9,3^{\mathrm{a}}$ & $0,9 \pm 0,8^{\mathrm{a}}$
\end{tabular}

$a, b$ Expoentes diferentes indicam diferença estatística na coluna $(P<0,05)$.

*T1: Tris-gema 5\% de glicerol;

T2: Tris-gema $5 \%$ de etilenoglicol;

T3: Tris-gema $2,5 \%$ glicerol $+2,5 \%$ de etilenoglicol.

\section{Discussão}

Os resultados obtidos demonstram que a associação entre glicerol e etilenoglicol é uma alternativa para criopreservação de sêmen canino, pois quando comparada a outros tratamentos utilizados obteve índices semelhantes ou superiores nas análises realizadas. Corroborando com resultados encontrados por Madeira et al., (2012) os quais não encontraram diferenças $(P>0,05)$ quanto a motilidade espermática e integridade de membrana entre o uso de glicerol na presença de água de coco comparado a associação de etilenoglicol e glicerol.

A realização do teste de penetração heteróloga em oócitos suínos, testada nesse trabalho, constitui uma técnica eficaz e muito mais prática que o 
RIZZOTO, G. et al. Efeitos da adição de glicerol e etilenoglicol associados sobre parâmetros de viabilidade espermática na criopreservação de sêmen canino. PUBVET, Londrina, V. 8, N. 22, Ed. 271, Art. 1808, Novembro, 2014.

teste de penetração homóloga. Devido à larga escala da produção e abate suíno a coleta dos ovários e as estruturas a serem encontradas em amostragem são elevadas. No caso da espécie canina é observado maior dificuldade na obtenção de ovários, uma vez que as estruturas utilizadas somente são obtidas a partir de ovariohisterectomias, caracterizando uma limitação para a aplicação dessa metodologia (Holstet al., 2000).

A taxa de manutenção da integridade de acrossoma obtida pelo T3, esta diretamente relacionada com os índices de taxa de penetração e número de espermatozoides/oócitos penetrados,uma vez que as lesões espermáticas mais comumente observadas têm localização acrossomal (Woelders et al.,1991).Alterações e lesões desta estrutura podem acarretar em perda das enzimas auxiliares e incapacidade de penetração no oócito (Christoph et al. 1999). No teste de penetração heteróloga em oócitos suínos com sêmen de Calomys laucha Corcini et al. (2012b), observaram correlação direta entre a integridade acrossomal e a taxa de penetração.

O T1 manteve taxa de integridade acrossomal semelhante ao T3, porém diferiu estatisticamente quanto a taxa de penetração e número de espermatozoides/oócitos penetrados, portanto sugere-se que este resultado esteja relacionado aos efeitos de sincronização e aceleração da reação acrossomal induzidos pelo glicerol durante o período de incubação para a realização do teste de penetração.

Tal fato já foi atribuído para sêmen ovino por Slavík (1987) em teste de penetração heteróloga com oócitos de hamster em que tratamentos previamente incubados com concentrações de 5 e $10 \%$ de glicerol apresentaram maior taxa de penetração com 30 minutos de incubação, enquanto que o pior resultado foi encontrado nas amostras com 120 minutos de incubação.

Outra possível causa foi abordada por alguns trabalhos (Aitken et al., 1983; Slavík et al., 1987) que descrevem o estresse osmótico como um indutor da reação acrossomal, estresse esse advindo do contato entre as células espermáticas com meio diluidor. Guthrie et al. (2002) comparando 
RIZZOTO, G. et al. Efeitos da adição de glicerol e etilenoglicol associados sobre parâmetros de viabilidade espermática na criopreservação de sêmen canino. PUBVET, Londrina, V. 8, N. 22, Ed. 271, Art. 1808, Novembro, 2014.

propriedades osmóticas de sêmen bovino em contato com diferentes crioprotetores, conclui que o etilenoglicol produziu menor estresse osmótico sobre as células espermáticas quando comparado ao glicerol. Sugere-se, portanto, que as maiores taxas de penetração encontradas $(p<0,05)$ para o T2 e T3 possam estar relacionadas com este fato, destacando que no T3 a associação dos crioprotetores pode ser a responsável pelo resultado positivo, enquanto que o T1 somente com glicerol apresentou o pior resultado. Tais resultados corroboram com Aitken et al., (1983), que em seu trabalho concluiu que o glicerol afetava negativamente a taxa de penetração de sêmen humano em oócitos de ratas.

Parks et al., (1982) descreveu a característica própria do glicerol em afetar os microtúbulos do citoesqueleto podendo prejudicar a interação com proteínas e gerar alteração na transdução de sinais, como por exemplo, na reação acrossomal como consequência sobre a taxa de penetração espermática. Tal fato também pode estar relacionado com os resultados inferiores de taxas de penetração e de número de espermatozoides por oócitos penetrados apresentado pelo T1.

O T2 apresentou o pior resultado na taxa de integridade acrossoma quando comparado aos outros tratamentos, sugere-se que tal fato se deva a melhor capacidade do glicerol em manter a estabilidade das membranas celulares e, por consequência, manter a membrana acrossomal durante o processo de criopreservação, devido a ligação dos grupamentos hidroxila do glicerol com os grupamentos fosfato das membranas celulares do espermatozóide (Kundu, 2000). O T3 também sinaliza a importância da associação de crioprotetores, pois juntamente com o T1 apresentaram melhor integridade de acrossoma que $\mathrm{T} 2$, o qual continha somente etilenoglicol.

Apesar do T2 juntamente com T3 manterem a taxa de penetração superior ao T1, não diferiram entre si quanto ao número de espermatozoides/oócitos penetrados. A explicação pode ter base nas propriedades negativas advindas da exposição aguda das células ao etilenoglicol, gerando alteração no metabolismo de fosfolipídios das 
RIZZOTO, G. et al. Efeitos da adição de glicerol e etilenoglicol associados sobre parâmetros de viabilidade espermática na criopreservação de sêmen canino. PUBVET, Londrina, V. 8, N. 22, Ed. 271, Art. 1808, Novembro, 2014.

membranas celulares e maior produção de radicais livres com potencial nocivo à viabilidade e plena função da célula, gerando redução na capacidade fertilizante do espermatozoide (Kramer, 1999).

A utilização de glicerol e etilenoglicol associados (T3) em substituição ao uso dos crioprotetores isoladamente na composição dos diluentes seminais para utilização na espécie canina, obteve taxas maiores ou iguais quanto a manutenção da qualidade seminal.

Dessa forma, denota-se a necessidade de realização de novos estudos avaliando efeitos tóxicos relacionados a concentração do crioprotetor no meio diluente e avaliação dos efeitos do tempo de incubação sobre a taxa de penetração espermática e número de espermatozoides/oócitos penetrados para sêmen canino.

\section{Conclusão}

A utilização de glicerol e etilenoglicol associados na composição do diluente tris-gema constitui uma alternativa para criopreservação de sêmen canino.

\section{Referências}

1. AITKEN, R.J.; WANG, Y.F.; LIU, J.; BEST, F.; RICHARDSON, D.W. The influence of medium composition, osmolarity and albumin content on the acrosome reaction and fertilizing capacity of human spermatozoa: development of an improved zona-free hamster egg penetration test. International Journal of Andrology, v.6(2), p.180-193,1983.

2. BOUCHARD,G.F; MORRIS,J.K; SIKES,J,D; YOUNGQUIST,R.S.: Effect of storage temperature, cooling rates and two different semen extenders on canine spermatozoa motility, Theriogenology, v.34, p.147-157,1990.

3. CASTRO, S.V; CARVALHO, A.A; SILVA, C.M.G; FAUSTINO, L.R; FIGUEIREDO, J.R; RODIGUES, A.P. Agentes crioprotetores intracelulares: características e utilização na criopreservação de tecido ovariano e oócitos. Acta Scientiae Veterinariae, v.39(2), pub. 197, 2011.

4. CHRISTIANSEN, I.J. Reprodução no cão e no gato. Editora Manole, São Paulo-SP, 1986.

5. CHRISTOPH, R. L.;DAULAT, R.P.T. The Role of Carbohydrates in the Induction of the Acrosome Reaction in Mouse Spermatozoa. Biology of Reproduction, v.60, p.94-101, 1999. 
6. CONCANNON, P.W; BATTISTA, M. Canine semen freezing and artificial inseminations. In Kirk RW (ed). Current Veterinary Therapy X: Small Animal Practice. Philadelphia, WB Saunders, p. 1247-1259, 1989.

7. CORCINI, C.D.; VARELA, A.S.; PIGOZZO, R.; RAMBO, G.; GOULARTE, K.L.; CALDERAM, K.; LEON, P.M.M.; BONGALHARDO, D.C.; LUCIA, T. Pre-freezing and post-thawing quality of boar sperm for distinct portions of the ejaculate and as a function of protein bands present in seminal plasma. Livestock Science (Print), v. 145, p. 28-33, 2012a.

8. CORCINI, C. D. ; STEPHAN, M. H.L. ; COLARES, E. P. ; SANTOS, E. C.S. ; VARELA JUNIOR, ANTONIO S. ; BONGALHARDO, D. C. ; LUCIA, T. JR . In vitro assays for vesper mice (Calomys laucha) sperm using heterologous substrates from nonrodent species. Journal of Experimental Zoology. Part A, Ecological Genetics and Physiology, v. 317, p. 96-102, 2012b.

9. CORLEY, R. A.; BARTELS, M. J.; CARNEY, E.W.; WEITZ, K.K.; SOELBERG, J. J.; GIES, R.A.; THRALL, K.D. Development of a Physiologically Based Pharmacokinetic Model for Ethylene Glycol and Its Metabolite, Glycolic Acid,in Rats and Humans. ToxicologicalSciences, v.85, p.476-490, 2005.

10. DE LOS REYES, M. Congelación de semen. In: GOBELLO, C. (Ed). Temas de reproducción de caninos y felinos por autores latino americanos. p. 17-26, 2004.

11. ENGLAND, G.C.W.: Cryopreservation of dog semen: a review. Journal of Reproduction and Fertility Supplements, v.4, p.243-255, 1993.

12. FAHY, G.M.: The relevance of cryoprotectant ' 'toxicity ' to cryobiology. Cryobiology, v.23, p.1-13. 1986.

13. FARSTAD, W. Semen cryopreservation in dogs and foxes. Animal Reproduction Science, v. 42 , p. 251-260.1996.

14. FORSBERG, C,L. Artificial insemination with fresh, chilled extended and frozen-thawed semen in the dog. Sem Vet Med Surge, v.40, p.48-58, 1995.

15. GANDINI, L.; LOMBARDO, F.; LENZI, A. ;, SPANÒ, M; Dondero, F. Cryopreservation and sperm DNA integrity. Cell and Tissue Banking, v.7, p. 91-98, 2006.

16. GRASA, P.; PÉREZ-PÉ, R.; BÁGUENA, O.; FORCADA, F.; ABECIA, A.; CEBRIÁN-PÉREZ, J.A.; MUIÑO-BLANCO, T. Ram Sperm Selection by a Dextran/Swim-Up Procedure Increases Fertilization Rates Following Intrauterine Insemination in Superovulated Ewes. JournalofAndrology, v.25, p. 982-990, 2004.

17. GUTHRIE, H.D.; LIU, J.; CRITSER, J.K. Osmotic tolerance limits and effects of cryoprotectants on motility of bovine spermatozoa. Biology of Reproduction, v.67, p.18111816, 2002.

18. HARRISON, R.A.P.; VICKERS, S.E. Use fluorescent probes to assess membrane integrity in mammalian spermatozoa. JournalofReproductionandFertility, v.88, p.343-352, 1990.

19. HOLT, W.V. Fundamental aspects of sperm cryobiology: the importance of species and individual differences. Theriogenology, v. 53, p. 47-58, 2000.

20. IGUER-OUADA, M. Vestegen long-term preservation of chilled canine semen: Effect of commercial and laboratory prepared extenders. Theriogenology, v.55, p.671-684, 2001. 
21. KAWAMOTO, A.; KAZUTOMO, O.; KISHIKAWA, H.; ZHU, L.; AZUMA, C.; MURATA, Y. Two-color fluorescence staining of lectin and anti-CD46 antibodY to assess acrosomal status. FertilityandSterility, v.71, p.497-501, 1999.

22. KRAMER, E.R. Cytotoxicity of short-chain alcohols. Annual Review of Pharmacology and Toxicology, v.39, p.127-150, 1999.

23. KUNDU, C.N.; CHAKRABORTY, J.; DUTTA, P.; BHATTACHARYYA, D.T.; GHOSH, A.; MAJUNDER, G.C. Development of a simple sperm cryopreservation model using a chemically defined medium and goat cauda epididymal spermatozoa. Cryobiology, v.40, p.117-125, 2000.

24. LOPEZ-BEJAR, M.; LOPES-GATIUS, F.; CAMON, J.; RUTLLANT, J.; LABERNIA, J. Development in vitro of rabbit embryos after freezing by two-step or ultra-rapid cooling methods. ZentralblVeterinarmed A, v.41, p.780-790,1994.

25. MACEDO, JR. M. C.; DESCHAMPS, J. C.; LUCIA, JR. T.; BORDIGNON, J.; SERRET, C.; RAMBO, G.; PIVATO, I.; SCHMITT, E. In vitro penetration of fresh and vitrified swine oocytes by homologous spermatozoa using different incubations systems. Animal Reproduction Science, v. 92, p. 334-348, 2006.

26. MACHADO, G. M. Efeito de Diferentes Protocolos de Percoll na Qualidade Espermática e na Produção In Vitro de Embriões Bovinos. Brasília: Faculdade de Agronomia e Medicina Veterinária, Universidade de Brasília,2007, 67p. Dissertação de Mestrado.

27. MADEIRA, V.L.H.; MONTEIRO, C.L.B.; SILVA,L.D.M.The effects of the combination of ethylene glycol and glycerol on the post-thaw quality of the dog semen preserved inpowdered coconut water (ACP-106C). Proceedings of the 7th International Symposium on Canine and Feline Reproduction - ISCFR, Whistler, Canada, 2012.

28. McLAUGHIN, E.A.; FORD, W.C.L.; HULL, M.G.R. The contribution of the toxicity of a glycerolegg-yolk-citrate cryopreservative to the decline in human sperm motility during cryopreservation.J. Reprod. Fertil. v.95, p. 749 - 754, 1992.

29. PENÃ, A.I., and LINDE-FORSBERG, C. Effects of Equex, one- or two- steps dilution, and two freezing and thawing rates on post-thaw survival of dog spermatozoa. Theriogenology, v.53, p. 859-875.2000.

30. SILVA,L.D.M; VERSTEGEN,J.: Comparisons between three different extenders for canine intrauterine insemination with frozen thawed spermatozoa. Theriogenology, v.44, p.571-579, 1995.

31. PARKS, J.E.; GRAHAM, J.K. Effects of cryopreservation procedures on sperm membranes. Theriogenology, v.38, p.209-222, 1992.

32. SLAVÍK, T. Effect of glycerol on the penetrating ability of fresh ram spermatozoa with zona-free hamster eggs. Journals of Reproduction \& Fertility LTD, v.79, p.99-103, 1987.

33. WATSON, P,F, Recent developments and concepts in the cryopreservation of spermatozoa and the assessment of their post-thawing function. Reproduction and Fertility Develpment, v.7, p.871-891, 1995.

34. WOELDERS, H. Overview of in methods for evaluation of semen quality. Journal of Reproduction and Fertility Supplement, v.1, p.145-164, 1991. 